\title{
Loss of vitamin $A$ in fortified edible oils and ghee during cooking in asian traditional style
}

\author{
Hifza Akhtar, Lubna Tahir, Shahid Mahmud and Shahnaz Hamid \\ Pakistan Council of Scientific and Industrial Research, \\ PCSIR Labs Complex Ferozepur Road, Lahore, Pakistan
}

\begin{abstract}
Vitamin 'A' is essential for normal growth and its deficiency causes night blindness, affects the regulatory function of skin and reduces the general resistance of organism to infection. This deficiency does not occur by using balanced diet or by fortification of staple food with appropriate amount of Vitamin 'A'. In Pakistan vitamin 'A' fortification is done in vegetable ghee/cooking oil. It is generally assumed that fortified amount of vitamin 'A' is fully destroyed when the food is cooked at high temperature.

The present study was focused to examine the effect of Pakistani traditional cooking style on the degree of destruction of vitamin 'A' mandatory fortified in the vegetable ghee/ cooking oils. The study indicates that there are some losses of Vitamin A of the fortified oils during cooking. However in case of deep fat frying destruction of added vitamin 'A' is more pronounced. The loss of vitamin 'A' was less than 50\%, when the food was cooked in Pakistani style in case of all the cooking oils/ vegetable ghee. In prolonged frying conditions substantial amount of vitamin 'A' (45\%) remains in the oil. Any how, this retention of vitamin 'A' is sufficient to meet the body requirements when oils/ ghee was fortified according to the prescribed Pakistan Pure Food Rules 1965 i.e. 33,000 IU per Kg.
\end{abstract}

Key words: Fortification Vit. A, Food Rules, Pakistani Cooking, Destruction of Vit. A.

\section{Introduction}

It is known that the vitamin 'A' deficiency is wide spread in Pakistan. Vitamin A is essential for normal growth. It affects the vision, causing night blindness, it has regulatory effect on the functions of skin and mucosa and it increases the general resistance of the organism to infection. The sign of Vitamin 'A' deficiency predominately includes blindness and the complication regarding eyes. Recent studies have shown that even mild vitamin 'A' deficiency causes an increase in morbidity and mortality due to intestinal and respiratory infections.

Vitamin 'A' is widely distributed in animals and plant food, in animal food it is found as preformed vitamin 'A' (Retinol) and in plant foods as pro-vitamin or beta-carotenes. Animal foods rich in Retinol are butter, eggs, cheese, whole milk and meat. In plant foods the cheapest source of vitamin ' $\mathrm{A}$ ' is green vegetables such as spinach, amaranth, which are found in abundantly in nature throughout the year in Pakistan. Vitamin 'A' also occurs in most green-yellow and orange fruits and vegetables e.g., papaya, mangoes, pumpkin and some roots such as carrots. Red palm oil is another source of vitamin 'A'. Normally Vitamin 'A' deficiency does not occur by using balanced diet or by fortification of staple foods with appropriate amounts of vitamin 'A'. Fortification of staple food items is considered the most cost effective long term strategy for the control and prevention of micro-nutrient (Vitamin 'A') deficiencies in developing countries like Pakistan vitamin 'A' occurs in nature pre-dominantly in an ester form rather than as the free alcohol (Al-Bacharach 1933, Chrichshank 1927). However, as free alcohol it is not non-resistant and has been isolated from a fat (Baxter, et al 1940).

In Pakistan the vitamin ' $\mathrm{A}$ ' fortification is done in Banaspati Ghee and Cooking Oils as Banaspati ghee/ oil is an integral part of the daily fat intake and is itself lacking in fat soluble vitamins. Pakistan at present has a legislation that demands the addition of 33,0000 IU/kg of vitamin 'A' in edible ghee 
and Oils which delivers about $1 / 3$ of the RDI (Required Daily Intake) of Vitamin 'A'. It is generally assumed that the fortified amount of Vitamin ' $\mathrm{A}$ ' is fully destroyed while the food is cooked in Pakistani style. The present study was undertaken to examine the effect of Pakistani cooking style on the degree of destruction of vitamin 'A' in the food.

Various studies (Proceeding 1998, Haffman et al 1994, Johnson 1997, Bavernfeiend 1953) to determine the stability of vitamin 'A' in fortified Ghee and Oils have been carried out in other countries but no authentic study has been carried out in Pakistan. On cooking different chemical reactions occurred which result the formation and degradation of different constituent of oil/ghee (Gopa et al., 1956, Nagy 1995 and Atwood 1995) and might be losses of Vitamin A. It is important because the traditional cooking practices in Pakistan are quite different from cooking and food preparation methods in other countries.

\section{Materials and Methods}

All the oils used for experimentation i.e., sunflower oil, soybean oil, corn oil and vegetable ghee were procured from the market and their vitamin 'A' quantity was evaluated by Spectrophotometric method before and after cooking and heating (US Pharmocopia XX 1985 British Pharmocopia 1932).

\section{Extraction of Vitamin 'A'.}

The vitamin fortified oils ( $5 \mathrm{gm}$ of each sample) were saponified with alcoholic $\mathrm{KOH}(20 \mathrm{ml})$, diluted with water $(100 \mathrm{ml})$ and non-saponifiable matter was extracted with diethyl ether. The ether extracts were dried over anhydrous sodium sulphate and filtered. The ether was evaporated and the residues were dissolved in propanon- 2 and the absorbance of the solution were read at 210,325 and $354 \mathrm{~nm}$. The corrected absorbance (A) were calculated by the use of the following equation ( ).

$$
{ }^{A}(\text { corrected }) 7\left(\mathrm{~A}_{325}\right)-2.625\left(\mathrm{~A}_{310}\right)-4.375\left(\mathrm{~A}_{334}\right)
$$

Known quantity of an oil was used for preparing the foods by heating the oils/ghee at 250-300 Centigrade. Pakistani cooking style was accomplished by adding condiments. Water and food items and then heating the mixture till the cooking of the food is complete. During cooking the temper- ature was noted at suitable time intervals. The oil was then extracted from the cooked/prepared food with hexane (B.P. $60^{\circ} \mathrm{C}$ ) and the vitamin A was extracted from the oil.

At the same time the other sample of ghee/oil was separately heated alone to about $250^{\circ} \mathrm{C}$ without adding condiments and food items. Samples were withdrawn at different time intervals and their Vitamin 'A' estimation was carried out for comparison. Peroxide values of all the oil were also determined at the same intervals of times along with Vitamin A.

\section{Peroxide value}

Peroxide value of the oils determined by following analytical method , AOCS 2003

\section{Result and Discussion}

Table (I, II) shows the percentage of vitamin 'A' losses in different oils and Banaspati ghee as a result of cooking (Table I) and heating alone (Table II) respectively. The results indicate that the percentage losses were more when the oil/ghee was heated alone at $250^{\circ} \mathrm{C}$ while losses were lower when foods were cooked in the fortified ghee/ oil in traditional Pakistani style. These results correspond to earlier studies

Table I: Residual vitamin ' $A$ ' in different oils in relation to the cooking in Pakistani style

\begin{tabular}{lccc}
\hline Oil/Ghee & Cooking Time & Temp. $\left({ }^{\circ} \mathrm{C}\right)$ & Vitamin A (\%) \\
\hline Sunflower Oil & $5 \mathrm{~min}$. & 100 & 97.7 \\
& $15 \mathrm{~min}$. & 110 & 79.4 \\
& $25 \mathrm{~min}$. & 150 & 65.2 \\
& $30 \mathrm{~min}$. & 175 & 64.8 \\
Corn Oil & $5 \mathrm{~min}$. & 110 & 92.4 \\
& $15 \mathrm{~min}$. & 130 & 74.5 \\
& $25 \mathrm{~min}$. & 150 & 62.4 \\
Ghee & $30 \mathrm{~min}$. & 160 & 61.7 \\
& $5 \mathrm{~min}$. & 100 & 88.4 \\
& $15 \mathrm{~min}$. & 110 & 75.2 \\
& $25 \mathrm{~min}$. & 130 & 63.7 \\
Canola Oil & $30 \mathrm{~min}$. & 170 & 62.0 \\
& $5 \mathrm{~min}$. & 105 & 85.8 \\
& $15 \mathrm{~min}$. & 165 & 77.4 \\
& $25 \mathrm{~min}$. & 155 & 64.8 \\
& $30 \mathrm{~min}$. & 160 & 65.8 \\
\hline
\end{tabular}


which show that the frying in open air, can destroy the vitamin 'A' more rapidly. The amount of loss depends on the number of times the same oil is used for frying. Bangash et al reported the in Physicochemical properties of some vegetable oil during deep frying (Bangash et al 2006). After the initial frying the losses of Vitamin A recorded was about $65 \%$ of original amount. After four repeated frying less than $40 \%$ vitamin A remained and after 12 consecutive frying whole of vitamin A was lost (proceedings National Consultative 1998)

It appears that cooking in the open air at high temperature and for longer time is more destructive. Similar earlier studies using margarine, indicate a similar losses pattern extreme condition. Studies show that the heating at $160^{\circ} \mathrm{C}, 180^{\circ} \mathrm{C}$ and $200^{\circ} \mathrm{C}$ for half an hour results on an average vitamin 'A' losses of 20\%,30\% and 50\% respectively (Haffman et al 1994). The results of the present experiments show similar trend din different oil in respect of the loss of vitamin 'A' as shown in Table I and Table II. The results indicate $<50 \%$ losses of Vitamin A in different Ghee/ Oils cooked in Pakistani style. The duration of cooking time was about half an hour for each test. The loss of vitamin ' $\mathrm{A}$ ' was abrupt in the first 20-25 minutes and after that period the loss was almost stable in all the cases. The loss of vitamin 'A' after cooking was about 35$39 \%$ as recorded in different oils. Any how it was maximum in corn oil (38.3\%) and minimum in canola oil (34.2\%), this difference may be due to the difference in the fatty acid composition of the two oils. The present study (Table II) shows a higher percentage of loses when the oils were heated alone in open air without condiments and food items. The loss of Vitamin A recorded was 50-55\% in different oils.

According to a finding the vitamin ' $\mathrm{A}$ ' resists destruction in the baking process like biscuits, cakes and breads. In the study 87 such products prepared with vitamin 'A' fortified margarine retained 80 to $100 \%$ of vitamin ' $\mathrm{A}$ ' while the conventional frying of potato chips resulted in a loss of about one quarter of the vitamin originally present in the frying fat vitamin ' $\mathrm{A}$ ' losses a are also related to the storage conditions. Studies carried out in Brazil showed that stability of vitamin ' $\mathrm{A}$ ' in oil stored in sealed cans is excellent after 9 months. However, if the same oil is kept in open containers or if the container is open and exposed to both oxygen and light, the vitamin ' $\mathrm{A}$ ' becomes unstable after six months and retention level of vitamin 'A' decreases to less than $50 \%$ after 9 months (Lotfi et al 1996). Several studies conducted in Brazil, Switzerland and India etc. affirm this facts.

Vitamin A and D are unstable when expose for length of time to light, air or heat, Moreover, some substances such as heavy metals and acids when present even in traces may accelerate their decomposition (Hoffman 1994). In practice the conditions vary widely and it is not possible to give precise and universally valid indicators of the stability of these fortified vitamin in edible ghee and oils.

Oil fortification is highly conducive in Pakistan scenario since the variation of oil consumption per person among rich and poor, rural or urban population divide is non significant (about $17 \mathrm{~kg}$ per year).

For some scientists fortification has been the issue of toxicity, due to the possibility of over rating of vitamin 'A'. However in real terms there is no such possibility, because even if a person consumes $100 \mathrm{gm}$ of oil, (which is practically not so), with 33 IU per gram daily intake of vitamin 'A', he is consuming $3300 \mathrm{IU}$ per day. With $50 \%$ cooking losses, the actual intake is only $1650 \mathrm{IU} /$ day which $75 \%$ of the RDI. According to UNICEF/ WHO report the safety level for vita-

Table II: Vitamin 'A' in different Oils in Relation to the cooking in Pakistani style

\begin{tabular}{lccc}
\hline Oil/Ghee & Cooking Time & Temp. $\left({ }^{\circ} \mathrm{C}\right)$ & Vitamin A (\%) \\
\hline Sunflower Oil & $5 \mathrm{~min}$. & 95 & 79.2 \\
& $15 \mathrm{~min}$. & 220 & 62.6 \\
& $25 \mathrm{~min}$. & 260 & 48.6 \\
& $30 \mathrm{~min}$. & 290 & 48.4 \\
Corn Oil & $5 \mathrm{~min}$. & 150 & 93.3 \\
& $15 \mathrm{~min}$. & 255 & 61.24 \\
& $25 \mathrm{~min}$. & 300 & 52.10 \\
Ghee & $30 \mathrm{~min}$. & 320 & 44.83 \\
& $5 \mathrm{~min}$. & 150 & 81.7 \\
& $15 \mathrm{~min}$. & 175 & 62.9 \\
& $25 \mathrm{~min}$. & 250 & 41.18 \\
Canola Oil & $30 \mathrm{~min}$. & 255 & 46.4 \\
& $5 \mathrm{~min}$. & 1560 & 84.42 \\
& $15 \mathrm{~min}$. & 210 & 49.23 \\
& $25 \mathrm{~min}$. & 250 & 49.82 \\
& $30 \mathrm{~min}$. & 250 & 50.41 \\
\hline
\end{tabular}


min ' $\mathrm{A}$ ' intake is $10,000 \mathrm{IU} /$ day and there is no possibility of hyper vitamin 'A' toxicity (WHO 1998, Nestel 1993, O'Brien 1993 and Combs et al., 1994).

Other studies showed almost $100 \%$ vitamin A retention in fortified soybean oil after 5months of storage in sealed cans. The stability of vitamin ' $\mathrm{A}$ ' during cooking was also found good. Boiling rice and pressure cooking of kidney beans in Brazil did not affect vitamin 'A' in fortified soybean oil (Favaro 1992).

Table III and IV show the peroxide value of different oil at different intervals of time recorded in the present study. It indicates a rise in peroxide value with the increase in the time of cooking. The results further indicate a decrease of vitamin 'A' retention with the increases in the peroxide value. It is, therefore, reasonable to conclude that there is an inverse relationship between the stability of the vitamin present in a fat and the peroxide value of the fat. The peroxide value expresses the degree of oxidation of the fat. Because the fats or oils when exposed to warm or moist air, they develop offtaste. This change is accelerated upon exposure to light heat

Table III: Percentage change in the peroxide value of different oils/ghee after cooking in Pakistani style for half hour

\begin{tabular}{lccc}
\hline Oil/Ghee & $\begin{array}{c}\text { Initial } \\
\text { peroxide } \\
\text { Value }\end{array}$ & $\begin{array}{c}\text { Final } \\
\text { peroxide } \\
\text { Value }\end{array}$ & $\begin{array}{c}\text { Percentage } \\
\text { change } \\
\text { in PV }\end{array}$ \\
\hline Sunflower oil & 2.80 & 3.6 & +32.09 \\
Corn oil & 3.56 & 4.52 & +27.17 \\
Canola oil & 5.75 & 9.33 & +62.33 \\
Ghee & 2.05 & 4.20 & +104.88 \\
\hline
\end{tabular}

Table IV: Percentage change in the peroxide value of different oils/ghee after heating for $1 / 2 \mathrm{hr}$

\begin{tabular}{lccc}
\hline Oil/Ghee & $\begin{array}{c}\text { Initial } \\
\text { peroxide } \\
\text { value }\end{array}$ & $\begin{array}{c}\text { Final } \\
\text { peroxide } \\
\text { value }\end{array}$ & $\begin{array}{c}\text { Percentage } \\
\text { change } \\
\text { in PV }\end{array}$ \\
\hline Sunflower oil & 2.80 & 6.79 & +142.54 \\
Corn oil & 3.56 & 6.44 & +80.95 \\
Canola oil & 5.75 & 6.94 & +72.92 \\
Ghee & 2.05 & 5.72 & +179.51 \\
\hline
\end{tabular}

as the oxygen affects the double bond of fatty acids to form peroxides. Hence the peroxidation occurs more ready in fats that have a high proportion of unsaturated fatty acids. Rancidity is caused by hydrolysis and oxidation so the higher the peroxide value, the less fit is the fat for human consumption and simultaneously there is greater the loss of vitamins. In other words a rancid fat is unsuitable for human and such fat would have lost most of vitamins it may originally have present in it.

The present study concluded that despite the losses of vitamin 'A' is of the fortified oils cooked in traditional Pakistan style, particularly the deep fat frying, does have an enhanced effect. However, the retention of vitamin A is still sufficient to meet the daily requirements. It is, therefore, stressed that the industry should follow the prescribed Pure Food Rule of 1975 and fortify all the edible ghee and oils with $33000 \mathrm{IU} / \mathrm{kg}$ of vitamin 'A'. Deep fat frying have more pronounced effect on the loss of vitamin ' $\mathrm{A}$ ' of the fortified oils/ghee.

As the results of present study indicate that the loss of vitamin 'A' in the Pakistan style cooking is less than 50\% and even at the worst frying conditions, substantial amounts of vitamin ' $\mathrm{A}$ ' remains in the oil. There are several advantages for using fortified vegetable oil/ghee as a medium for vitamin 'A' and some of these advantages are the lower cost, available technology, stability and better absorption and most important is the providence of viamin A to consumer of the population of under developed country like Pakistan to overcome deficiency of vitamin A.

\section{References}

Al-Bacharach, Laster Smith E. and Stevenson SG 1933. Some properties of ergestrol and calciferol. Analyst 58: 128-35.

Atwood SJ 1995. Stability of vitamin A in fortified vegetable oil and corn soy blend used in child feeding programs in India. Journal of food composition and analysis. 8(1): 32-44.

Bangash FK and Khattak H 2006. Effect of deep fat frying on Physicochemical of sitybum marrianum and sunflower seed oils. Jour. Chem. Soc. Pak. 28: 121-124. 
Bauernfeind JC 1953. Synthetic vitamin A and food fortification. Food Engineering. 81

Baxter JG and Robeson CD 1940. Crystallization of Vitamin A palmitate and Vitamin A alcohol. Science 92: 203-4.

British Pharmacopia. 1932. pp: 833.

Combs GF, Dexter PB, Horton SE and Buescher R 1994. Micronutrient fortification and enrichment of P.L. 480 Title II commodities: recommendations for improvement. OMNI, Arlington, VA.

Crichshank EM Hart EB and Malp JC 1927. Vitamin A and Vitamin D content of Cod liver meal. Poultry Sci. 7: 919.

Favaro RMB 1992. Evaluation of the effect of heat treatment on the biological value of vitamin A fortified soybean oil. Nut. Res. 12: 1357-1636.

Gopal SH and Ketyum FK 1956. Vitamin A and D in Ghee and Vanaspati. J. of Scientific and Industrial Research. 15c (2): 48-51.

Haffman F and Roache La 1994. The Fortification and Coloring of Edible Fats and Oils. Technical Bulletin. A.G. Switzerland.

Jhonson LD 1997. Oils, Fats and Margarine; Overview of Tehcnology in food Fortification to End Micronutirent Malnutrition. (1998). Stae of the Art pp: 22-26. The Micronutrient Initiative International Development Research Centre, Ottawa, Canada.
Lotfi M, Mannar MGV Merx, RJHM and Naber-Van di Heuvel P 1996. Micronutrient Fortification of Foods; Current practices. Research and opportunities. The Micronutrient Initiative International Development Research Centre, Canada.

Nagy K 1995. Fortification of Edible Fats and Oils with Vitamin A and D, Hoffman LaRoche.

Nestel P 1993. Food fortification in developing countries. U.S. Agency for International Development.

O'Brien A and Roberton D 1993. In The Technology of Vitamins in Food, ed. P. B. Ottaway. Chapman Hall, Glasgow.

Proc. National Consultative Meeting on Vitamin A Fortification of Banaspati Ghee and Edible Oils (1998) Islamabad. Pakistan

US Pharmocopia XX 1985. Vitamin A Assay Chemical Test. p: 33 .

WHO 1998. Safe vitamin A dosage during pregnancy and lactation. Document WHO/NUT/98 4; WHO, Geneva, Switzerland.

Manuscript received on 26 September 2010; revised on 02 August 2011; accepted on 18 September 2011. 